\title{
Cultura Contemporânea e Medicinas Alternativas: Novos Paradigmas em Saúde no Fim do Século $\mathbf{X X}^{1}$
}

MADEL T. LUZ

$\mathrm{O}$ artigo trata das relações atuais entre cultura, medicina, e as chamadas medicinas alternativas, de uma perspectiva analítica macrossociológica. Algumas hipóteses interpretativas são levantadas para explicar a grande profusão de novas terapias e sistemas terapêuticos na sociedade contemporânea, entre as quais a da existência de uma dupla crise - sanitária e médica - que afeta as relações tradicionais existentes entre cultura e medicina. Além disso, uma hipótese subsidiária interpreta essa eclosão de terapias e sistemas como fruto da própria racionalidade médica hegemônica na cultura ocidental, que centraliza a doença como elemento estruturante de seu paradigma e institui a ciência (das patologias) como base da racionalidade médica ocidental, praticamente excluindo a milenar questão da arte de curar como foco central da prática e do saber médico.

Palavras-chave: Cultura; medicina; medicinas alternativas. 


\section{A Crise da Saúde e a Crise da Medicina no Final do Milênio}

Este artigo levanta algumas hipóteses interpretativas sobre o crescimento, nas sociedades ocidentais, da busca e do uso dos sistemas terapêuticos comumente denominados "medicinas alternativas", entre os quais se incluem não apenas as medicinas tradicionais das culturas nacionais (ou mesmo regionais), como também as medicinas tradicionais provindas do Oriente, e a medicina homeopática.

O termo "medicinas alternativas" não será aqui objeto de discussão. Será aceito como o termo institucional que efetivamente é, pois foi originalmente enunciado pela Organização Mundial de Saúde (OMS) em 1962, definindo, no singular (medicina alternativa), uma prática tecnologicamente despojada de medicina, aliada a um conjunto de saberes médicos tradicionais. Foi proposta como "alternativa" à medicina contemporânea especializante e tecnocientífica, no intuito de resolver os problemas de adoecimento de grandes grupos populacionais desprovidos de atenção médica no mundo.

Posteriormente, passou a designar práticas terapêuticas diversas da medicina científica, geralmente adversas a essa medicina. Atualmente o termo se reveste de grande polissemia, designando qualquer forma de cura que não seja propriamente biomédica. Por este motivo, não se considera aqui o termo "medicinas alternativas" um conceito, mas uma etiqueta institucional.

O crescimento dessas "medicinas alternativas" tem-se verificado tanto em países conhecidos como do Primeiro Mundo, como nos ditos do Terceiro Mundo - entre os quais se situam os países da América Latina - a partir, basicamente, da segunda metade dos anos 70 , conhecendo um auge na década de 80 .

As tentativas de interpretação aqui apresentadas são baseadas na produção bibliográfica de dois projetos de pesquisa por mim coordenados, desenvolvidos no Instituto de Medicina Social da Universidade do Estado do Rio de Janeiro desde1982, sendo o primeiro sobre a Homeopatia no Brasil (desenvolvido entre 1982 e 1990) e o segundo, atualmente em sua terceira fase, sobre sistemas médicos comparados, intitulado "Racionalidades Médicas" (de 1991 até hoje).

As hipóteses interpretativas apresentadas, macroanalíticas, são principalmente de natureza político-institucional e socioeconômica, embora os aspectos culturais da questão estejam bastante presentes e sejam analisados 
com cuidado. Entretanto, não tematizo, neste trabalho, aspectos socioculturais em micronível de análise, relativos a atores específicos envolvidos na questão das "medicinas alternativas", tais como médicos, terapeutas, pacientes, religiosos etc., em suas relações de encontro/desencontro, conflito/harmonia ou negociação. Também não está tematizada, apesar de considerada importante, a geração de novas terapias a partir de indivíduos ou grupos sociais específicos.

Tento tematizar aqui o desenvolvimento dessas "medicinas" a partir do que considero uma dupla crise na sociedade atual: sanitária e médica, envolvendo culturalmente as relações medicina-sociedade, neste final de século, como base para o sucesso das "medicinas alternativas". É verdade que não caracterizo tal "crise" como simples efeito da evolução do capitalismo, em seu momento atual de mundialização, de transformação da base produtiva, das relações do trabalho, do consumo etc., porém situo as raízes socioeconômicas do que tematizo como crise sanitária e crise da medicina.

Proponho, além disso, como hipótese suplementar, a questão da própria racionalidade médica em sua relação com a cultura contemporânea como um dos elementos básicos explicativos da dupla crise que analiso, bem como da fuga da clientela, em busca de outras racionalidades terapêuticas, que priorizem em seu modelo o sujeito doente e seu cuidado.

\section{Crise da Saúde}

Acredito que o surgimento de novos paradigmas em medicina esteja ligado a diversos acontecimentos, situações e condicionamentos complexos, de natureza ao mesmo tempo socioeconômica, cultural e epidemiológica. Entre esses acontecimentos fundamentais, destaca-se um conjunto de eventos e situações que podem ser denominados de "crise da saúde", característica do final do século e do milênio.

A crise da saúde pode ser vista, em primeiro lugar, como fruto ou efeito do crescimento das desigualdades sociais no mundo, consideradas aqui as sociedades do capitalismo avançado (predominante no Primeiro Mundo), as do capitalismo dito dependente (predominante no Terceiro Mundo), as sociedades oriundas dos destroços do socialismo, e o conjunto de países subdesenvolvidos do Continente africano, às vezes denominados de Quarto Mundo. Este todo forma um conjunto submetido às leis de uma economia capitalista chegada a 
um estágio de internacionalização e dominância completa sobre o planeta, processo que economistas e cientistas políticos têm chamado de "globalização".

Essa crise se torna particularmente aguda nas sociedades onde há desigualdade social profunda, como no continente latino-americano, com a grande concentração de renda atual gerando problemas graves de natureza sanitária, tais como desnutrição, violência, doenças infecto-contagiosas, crônicodegenerativas, além do ressurgimento de velhas doenças que se acreditavam em fase de extinção, tais como a tuberculose, a lepra, a sífilis e outras doenças sexualmente transmissíveis, que se aliam a novas epidemias como a AIDS. Tudo isto, sem mencionar o consumo de drogas como cocaína e crack, que tem crescido em proporção maior entre nós que nos países do Primeiro Mundo.

Todas são questões que poderiam ser controladas, ou mesmo prevenidas, com políticas sociais adequadas, se os governos desses países estivessem comprometidos com a saúde da população, e não com a atual onda políticoideológica neoliberal, que tem gerado políticas econômicas e sociais agravadoras do quadro sanitário descrito. Essa questão, muito discutida pelos mesmos economistas e cientistas políticos que discutem a globalização como fato econômico, não constitui objeto deste trabalho, ficando aqui apenas enunciada como um dos elementos básicos da crise sanitária, que motivará, indiretamente, a busca de outra racionalidade em saúde pelas populações.

Além disso, devido em grande parte às condições socioeconômicas que originam a crise sanitária, desenvolve-se atualmente no mundo capitalista o que sociólogos franceses, que tratam das relações entre saúde e cidade, entre os quais Michel Joubert, têm denominado de "pequena epidemiologia do malestar", ao analisarem uma síndrome coletiva que se poderia definir como biopsíquica, com grande repercussão na saúde física e mental da força de trabalho, caracterizando-se por dores difusas, depressão, ansiedade, pânico, males na coluna vertebral etc., que atinge milhões de indivíduos das populações de quase todos os países nas grandes cidades, ocasionando uma situação permanente de sofrimento para os cidadãos e de perda de muitos milhões de dólares anuais para as economias desses países, em função de dias de trabalho perdidos.

Creio que esse "mal-estar" coletivo pode ser visto como um fenômeno de natureza tanto sanitária como cultural, que tem suas raízes não apenas nas condições de trabalho do capitalismo globalizado, mas na própria transformação recente da cultura que é seu fruto. 
Verifica-se, com essa transformação, a perda de valores humanos milenares nos planos da ética, da política, da convivência social e mesmo da sexualidade, em proveito da valorização do individualismo, do consumismo, da busca do poder sobre o outro e do prazer imediato a qualquer preço como fontes privilegiadas de consideração e status social.

A brusca mudança de valores nos campos mais importantes do agir e do viver humanos, sugerida ou amparada por meios poderosos de difusão cultural como a televisão, o rádio, a imprensa escrita em geral e, principalmente, a publicidade e a propaganda, que atingem pesadamente as populações de quase todo o planeta, vem causando uma situação de incerteza e apreensão sobre o modo de se conduzir e o que pensar e sentir em relação a temas básicos como sexualidade, família, nação, trabalho, futuro como fruto de uma vida planejada etc.

Além disso, a unificação mundial das fontes de informação e difusão cultural vem ocasionando uma quebra de padrões nas culturas nacionais, e mesmo regionais dos países, substituindo-se antigos padrões de identidade cultural por padrões homogêneos próprios da cultura de massas. Paradoxalmente, essa homogeneização "pelo alto", isto é, a partir do central, proporcionou uma fragmentação "por baixo", isto é, a partir da esfera local, tendo havido o ressurgimento - ou pelo menos a recuperação, ou a revalorização - de antigos padrões e formas particulares de expressão de cultura, entre os quais figuram aqueles relacionados à saúde e à medicina. Penso, entretanto, que a vivência coletiva dessa situação de mutação cultural tem gerado um quadro de inquietação e mal-estar social, com repercussões concretas na saúde dos cidadãos das diversas sociedades.

\section{Crise da Medicina}

A crise da medicina, que deve ser distinguida do grande quadro que esbocei acima como crise da saúde, mas que dele não pode ser desligado, deve ser analisada em vários planos de grande significação, tanto em termos socioeconômicos como culturais. Nomearei aqui os principais, sem pretensão de aprofundamento, em face dos objetivos maiores deste trabalho. Primeiramente destaco o plano institucional, por muitos considerado o principal, na medida em que se traduz nos programas de atenção médica, sobretudo aqueles destinados às populações de baixa renda. Em seguida, destaco o plano ético imediatamente 
ligado à prática médica, na medida em que destaca a perda ou a deterioração atual da relação médico-paciente, com a objetivação dos pacientes e a mercantilização das relações entre o médico e seu paciente, visto atualmente mais como um consumidor potencial de bens médicos que como um sujeito doente a ser, se não curado, ao menos aliviado em seu sofrimento pelo cuidado médico.

Imediatamente após, destaco o plano da eficácia institucional médica, no qual deve ser destacada a perda, pela medicina atual, de seu papel milenar terapêutico, isto é, de sua função de arte de curar em proveito da diagnose, com o avanço das ciências do campo biomédico, através da investigação cada vez mais sofisticada de patologias, sem igual consideração pelos sujeitos doentes e por sua cura.

Em seguida, sublinho a grave questão da bioética, implicada na investigação biomédica, que se desenvolve, atualmente, em progressão quase exponencial no âmbito microanalítico jamais alcançado pela ciência: o nível genético, mais uma vez sem uma cuidadosa consideração do sujeito humano, aí envolvido direta ou indiretamente.

Deve ser considerado para análise também o plano corporativo, isto é, o da profissão médica, que implica não apenas a questão da ética profissional em termos das relações intracategorias (questão das especialidades médicas), como as relações intercategorias da área de atenção à saúde (relações médicos/ terapeutas, ou médicos e outras profissões, como psicólogos, enfermeiros, assistentes sociais etc.) que chegaram atualmente a um nível de grave competição, perceptível nos serviços públicos de saúde. Aqui também deve ser destacada a questão das relações entre profissionais médicos e cidadãos, sobretudo no que concerne à clientela dos serviços públicos, caracterizada muitas vezes por conflito ou hostilidade.

Não pode ser esquecido tampouco o plano pedagógico, da educação médica (médicos: como, para que e para quem?), e o político-institucional, da formação de recursos humanos para atuarem na área biomédica em seus diversos níveis - técnico, administrativo e de planejamento. Deve ser destacada aí a questão da perda progressiva da capacidade das escolas ou faculdades da área de atenção à saúde para formar profissionais aptos para resolver, ou mesmo equacionar, problemas de saúde/doença de grande parte da população, sobretudo nos países de grandes desigualdades sociais, isto é, os do Terceiro e Quarto mundos. 
Deve ser ressaltado, entretanto, que o que aqui designo de "crise da medicina" não significa absolutamente uma crise em seu modelo de produção de conhecimento, ou uma estagnação nas suas investigações. Não se trata de uma crise do que Foucault designaria de saber médico. Muito ao contrário, em termos de "ciência das doenças", a medicina vai muito bem, revolucionando-se constantemente através da produção dos ramos disciplinares da biociência que mais lhe são próximos.

Até este momento analiso a "crise" muito mais nos planos ético, político, pedagógico e social. Outros planos poderiam também ser destacados para análise, como freqüentemente o são, em planejamento de saúde: o plano econômico, dos custos crescentes da tecnologia médica e seus efeitos institucional e social; o plano da irracionalidade da organização da medicina, centrada num modelo de atenção médica hospitalar, em detrimento das necessidades de atenção primária da população, entre outros. Não é o propósito deste trabalho analisá-los, embora sejam aspectos político-institucionais importantes a serem considerados na "crise da medicina" que tento esboçar.

Saliento, entretanto, que sempre que se analisam os ingredientes da questão social da medicina na sociedade atual, esses aspectos são privilegiados na análise de gerentes e planejadores, além de políticos do setor Saúde, sem que se levem em consideração os aspectos anteriores que venho mencionando nestas páginas. Neste caso, a "irracionalidade da medicina" se resume a um problema puramente gerencial ou, no máximo, de políticas públicas adequadas que é necessário implantar, controlar e avaliar.

Finalmente, deve ser destacado aqui o plano do que designo de Racionalidade Médica $^{4}$, na medida em que o próprio paradigma que rege a medicina contemporânea afastou-se do sujeito humano sofredor como uma totalidade viva em suas investigações diagnósticas, bem como em sua prática de intervenção. Também, na medida em que esse sujeito humano sofredor deixou de ser o centro de seu objeto (como investigação) e de seu objetivo (como prática terapêutica). A situação desse duplo afastamento gerou uma dupla crise, na saúde das populações e na medicina como instituição, detectada a partir da segunda metade do século $\mathrm{XX}$, que parece ter-se agudizado nos últimos vinte anos. Foi essa dupla crise que descrevi brevemente na introdução deste trabalho. 


\section{Medicina e Cultura no Final do Milênio}

Tomo como marco histórico simbólico da dissociação entre saúde, medicina e cultura a conferência de Alma Ata, realizada na União Soviética, em 1978. Nela o diretor geral da Organização Mundial da Saúde declarou a incapacidade da medicina tecnológica e especializante para resolver os problemas de saúde de dois terços da Humanidade, fazendo um apelo aos governos de todos os países para o desenvolvimento de formas simplificadas de atenção médica destinadas às populações carentes no mundo inteiro, com o correspondente esforço no campo da formação de recursos humanos, utilizandose, para isso, os próprios modelos médicos ligados às medicinas tradicionais. “Saúde para todos no ano 2000" foi o lema então lançado.

Aparentemente, às vésperas do terceiro milênio, nunca estivemos tão longe de tal propósito, pois já são três quartos da população mundial que carecem de saúde, seja no sentido mais amplo, de condições coletivas adequadas e salubres de existência, seja no sentido mais estrito, de pessoas atingidas individualmente em suas funções orgânicas e sistemas psicobiológicos, gerando assim um quadro de crise sanitária internacional. Levando-se em consideração o grande e continuado desenvolvimento da tecnologia e da ciência no campo da medicina, e sua incapacidade para reverter tal quadro, a busca de outra racionalidade em saúde por parte de distintos grupos sociais que conformam clientelas de cuidados médicos, e mesmo por parte de profissionais terapeutas, torna-se uma explicação razoável para o sucesso de sistemas terapêuticos regidos por paradigmas distintos daqueles da medicina científica.

Além disso, por paradoxal que pareça à primeira vista, a própria ideologia hedonista de valorização do corpo, da individualidade, da beleza e da conservação da juventude, associada à fisicultura, ensejou o aparecimento e o desenvolvimento de novas representações de corpo, indivíduo, pessoa e salubridade, que tendem a se opor às representações e concepções de temas classicamente ligadas à cultura médica, tais como as de máquina ou autômato altamente organizado, no caso de corpo; de divisão dualista corpo/mente, no caso de indivíduo, e de separação homem/natureza, no caso de pessoa.

As novas representações sobre esses temas, apoiadas na divulgação, pela mídia, de padrões "naturais" de consumo, de beleza e de salubridade, tendem a valorizar um neonaturismo ecológico como fonte de saúde, e a buscar a superação da representação homem/máquina na cultura contemporânea. 
Tais representações, por outro lado, encontram suporte, ainda que em termos de negação, num conjunto de fatos recentes de natureza ambiental. Aqui é necessário mencionar a deterioração progressiva do meio ambiente planetário na segunda metade do século, produzida pelo desenvolvimento industrial apoiado em uma tecnologia invasiva e predatória da natureza, com os conhecidos efeitos da poluição atmosférica, pluvial e marítima, da erosão, do assoreamento, da desertificação e da depredação de sítios e nichos insubstituíveis da natureza, colocando-se em risco a diversidade biológica e a própria sobrevivência da Humanidade.

Uma grande inquietação social está associada a essa "perda da natureza", se se pode qualificar assim a preocupação do movimento ecológico surgido nos últimos vinte anos, e que não se limita a tematizar a questão do meio ambiente, mas também a questão da vida como um todo, aí incluindo-se basicamente a questão da saúde humana. A recuperação das categorias de vida, saúde, higiene, entre outras, está ligada a essa "consciência ecológica" característica do fim do milênio. O que também leva à procura de outro paradigma em saúde, ao menos nas grandes cidades, ou nas regiões mais urbanizadas do mundo atual. Neste contexto, a medicina tecnológica tende a ser representada como antinatural e antiecológica, e a busca de medicinas "naturísticas" ganha adesão de camadas importantes das populações urbanas.

\section{As Medicinas Alternativas e a Atual Cultura em Saúde}

O surgimento de novos modelos em cura e saúde a partir da segunda metade do século XX, sobretudo com o movimento social urbano denominado contracultura, desencadeado nos anos 60 e prolongado durante os anos 70 nos EUA e na Europa, incluiu a importação de modelos e sistemas terapêuticos distintos daqueles da nossa racionalidade médica, e mesmo opostos a ela, numa atitude, do ponto de vista deste trabalho, de rejeição cultural ao modelo estabelecido, em função das razões já apontadas.

Além da importação de antigos sistemas médicos, como a medicina tradicional chinesa e a ayurvédica, a reabilitação das medicinas populares ou folk do país (como as xamânicas ou as ligadas às religiões afro-indígenas) foi um evento histórico que atingiu não apenas o Brasil, mas o conjunto dos países latino-americanos, principalmente durante a década de 80 , basicamente nos grandes centros urbanos. 
Tal evento pode ser evidenciado pelos seguintes indícios, entre outros: grande desenvolvimento, nos centros urbanos, de farmácias e lojas de produtos naturísticos tradicionais ou recentes; reaparecimento, em feiras populares urbanas, do "erveiro" (vendedor de plantas medicinais) como agente de cura, e aparecimento, no noticiário da grande imprensa escrita e televisiva, de reportagens freqüentes sobre os efeitos curativos de terapias ou práticas terapêuticas não-convencionais, denotando aumento da procura das mesmas por um número significativo de pessoas.

Esse evento assinala também o boom das medicinas tradicionais complexas na sociedade ocidental, que passaram a ser denominadas de terapias, ou medicinas "alternativas", e começaram a disputar espaços não apenas junto à clientela liberal ou privada, mas também nos serviços de saúde, demandando uma legitimação institucional até então não reconhecida ou concebida, e obtendo paulatinamente espaços de inserção na rede pública. É necessário, entretanto, que se olhe agora um pouco mais de perto essas "medicinas alternativas", dada sua grande diversidade interna, bem como sua forma diferenciada de inserção e enraizamento na cultura dos países latino-americanos.

Podemos distinguir três grupos de "medicinas alternativas" na América Latina, todos com demanda atual significativa por parte da população, de acordo com os diferentes países, em função de seu estágio de maior ou menor desenvolvimento urbano-industrial, e de sua história cultural: a medicina tradicional indígena, que com mais precisão se deveria escrever no plural, devido à sua variedade, embora tenha um mesmo paradigma básico; a medicina de origem afro-americana, também plural, embora mais homogênea que a primeira; e as medicinas alternativas derivadas de sistemas médicos altamente complexos, recentemente introduzidas na cultura urbana dos países ocidentais.

Em primeiro lugar, deve ser salientada a mais antiga e persistente, apesar de todas as agressões culturais sofridas, que é a medicina de origem indígena, xamânica ou não-xamânica, nativa dos países que sofreram a colonização lusoespanhola. Tal medicina tradicional, também identificada como aborígine, primitiva, natural, não-formal, ou simplesmente medicina indígena, é realmente a expressão viva das culturas locais em muitos rincões do continente americano. Poder-se-ia afirmar, inclusive, sem medo de incorrer em erro, que constitui um dos aspectos mais dinâmicos de reprodução social dos grupos étnicos e de sua interação com as sociedades nacionais. 
As práticas curativas domésticas e públicas dos grupos étnicos e das populações mestiças com forte ascendente nativo são parte indissociável das formas de vida, das cosmovisões e dos sistemas de valor e de significação das culturas locais. Esse tipo de práticas, com seus recursos materiais, em geral erbolários, de vez em quando redescobertos pelo olhar civilizador do Ocidente, faz parte de verdadeiros sistemas médicos complexos, cuja racionalidade evidentemente difere do logos iluminista newtoniano.

As medicinas tradicionais indígenas, fortemente enraizadas nas culturas locais dos países sul-americanos, sobreviveram como puderam ao massacre cultural do período histórico da colonização, e ao da modernização que lhe sobreveio com o século XIX. Caracterizam-se como sistemas de cura nos quais a integração ou harmonia homem/natureza, e natureza/cultura é um sinônimo do que designaríamos, em nossa cultura, de equilíbrio para os indivíduos, e uma garantia de saúde para a comunidade.

$\mathrm{O}$ adoecimento é gerado pela desarmonia entre esses elementos fundamentais da vida, e restaurar a saúde, através da intervenção de xamãs, ou brujos, ou outros agentes de cura, é restabelecer a harmonia entre esses termos nos sujeitos, sempre vistos como um todo socioespiritual inserido na natureza.

Ali onde sobrevivem concepções "tradicionais" sobre a vida a enfermidade e a morte, e onde se conservam saberes e práticas médicas autóctones que reconhecem tipos de "males" não equiparáveis às doenças ocidentais, existe um pensamento diferente, que se convencionou denominar de "mágico-religioso" em Antropologia clássica. Sob a etiqueta genérica de formas mágico-religiosas, os atos terapêuticos gerados no interior dos sistemas médicos indígenas têm sido habitualmente reduzidos a um estereótipo de tipo xamânico, quando este é apenas uma das facetas da racionalidade médica indígena. Em muitas das cosmovisões indígenas, entretanto, o adoecimento é apenas um aspecto de uma categoria mais ampla, onde também se inclui a morte, o azar, os acidentes, o feitiço, o mau-olhado e outras desgraças.

Certamente a própria natureza oferece os meios para o restabelecimento ou cura, através do recurso terapêutico que a cultura ocidental denominou fitoterapia. As ervas, os minerais e não raramente os animais de cada região fornecem as bases terapêuticas desse sistema de cura, não exclusivamente operado por xamãs. Os "erveiros" são também agentes de cura bastante importantes no sistema, assim como farmacêuticos populares, trabalhando em farmácias de ervas e produtos naturais. As "benzedeiras" e as parteiras são 
outros tantos agentes de cura contemporâneos que utilizam as formas de intervenção terapêutica derivada da tradição indígena na América do Sul, sobretudo no imenso território compreendido pela floresta e pelos rios ligados ao Amazonas.

Numerosas etnografias dão conta da existência atual da grande variedade de especialistas, ofícios e atos terapêuticos nos grupos sociais que habitam as regiões dos Andes e da Amazônia. As redes de intercâmbio e sistemas de apoio inter e intra-regionais, xamânicos e não-xamânicos, se reativaram e revitalizaram, apoiados na modernidade, que oferece vias de comunicação maiores e mais velozes.

Em alguns países da América do Sul, como na Colômbia, na Bolívia, no Equador e mesmo no Brasil, embora praticamente restrita ao neoxamanismo, a magia atribuída a alguns dos agentes de cura indígenas é impressionante; seu poder se exerce sobre a vida e a morte, sobre a sorte e a má sorte e, evidentemente, sobre as invejas e as maledicências dos "forasteiros". A procura da medicina tradicional indígena pelas populações pobres ou marginalizadas permanece, nessas regiões, um fato inconteste, e, em países como o Equador, 60 a 70\% da população fazem uso dos recursos de tal medicina.

Em seguida à medicina tradicional indígena, há uma medicina em parte também originalmente xamânica, mas marcadamente mais religiosa que a primeira, relacionada com a população de origem africana, introduzida nos países da América do Sul e América Central através da escravidão praticada no continente pelos colonizadores europeus, basicamente a partir do século XVII e desenvolvida durante os séculos XVIII e XIX com o tráfico de escravos vindos do continente africano.

Essa medicina tradicional, ou mais exatamente, esse sistema de cura complexo, que se enraizou fortemente na cultura das grandes fazendas e na dos centros urbanos por influência da força de trabalho escrava, também tem uma base terapêutica fortemente ancorada na fitoterapia. Entretanto, embora empregue a natureza como recurso básico de intervenção de cura, é inegavelmente mais espiritualista em sua abordagem dos fenômenos de adoecimento individual e grupal, e seu agente de cura mais importante é normalmente um sacerdote (ou sacerdotisa), através da figura do pai de santo ou mãe de santo, que opera terapeuticamente intermediando entidades espirituais, divindades de diversas hierarquias, geralmente em rituais em que possessão e exorcismo podem ter papel importante na cura. 
Pertencendo a uma cultura de resistência, originária das culturas das tribos africanas, foi transmitida de geração a geração de um modo socialmente muito eficiente, tradicional, através do ensino iniciático e da filiação dos iniciados e devotos leigos a "casas" e linhas de espiritualidade ligadas a diversas divindades de origem africana. Seus praticantes, devotos e sua clientela podem ser encontrados há quase um século nos centros urbanos de vários países da América do Sul e Central (no Caribe) e, no Brasil, através da umbanda e do candomblé.

Esse sistema de cura tem atualmente enorme penetração nos centros urbanos brasileiros, nas camadas médias e baixas da população. Mesmo os pacientes que se tratam pela medicina convencional freqüentemente buscam as medicinas espiritualistas da umbanda, do candomblé e dos centros kardecistas, utilizando-as sincreticamente como forma terapêutica popular. As chamadas medicinas populares no Brasil são grandemente impregnadas por esse sistema tradicional ${ }^{5}$.

Em geral tal sistema de cura se encarrega do tratamento de "doenças espirituais" ou de origem espiritual (mau-olhado, feitiço etc.), ou então daquelas doenças para as quais a medicina ocidental não oferece ainda perspectiva de cura, ou cujo tratamento é considerado como excessivamente invasivo, como câncer, AIDS e várias doenças crônicas. Cobre, portanto, uma gama enorme de doenças orgânicas e não-orgânicas, empregando como meios terapêuticos, além dos "passes" espirituais, a fitoterapia e a prática de uma homeopatia popular de tradição secular na sociedade brasileira. Além disso, exige certas disposições, comportamentos e atitudes dos pacientes "em tratamento", como dietas especiais, formas de sentir e de pensar que facilitem a cura, além de oferendas de preces e alimentos, ou doações materiais às divindades ("orixás", no caso do Brasil), no sentido de propiciar o restabelecimento do paciente.

Finalmente, há um grupo de novas terapias designadas como "alternativas", "paralelas" ou "complementares" à biomedicina, introduzi das nos últimos vinte anos na cultura urbana dos países latino-americanos. Geralmente trata-se de terapias derivadas de sistemas médicos complexos tradicionais que têm sua própria racionalidade, como a medicina tradicional chinesa, a medicina ayurvédica, ou ainda a homeopatia. É dessas "medicinas alternativas" que me interessa falar detidamente neste trabalho, pois são elas que têm tido atualmente um grande crescimento, em termos de consumo, em nossa sociedade. São também aquelas que têm mais chance, por sua "tradutibilidade terapêutica", em termos de medicina ocidental, de se legitimarem 
frente à ciência e às instituições de saúde. São elas que têm sido o objeto do projeto "Racionalidades Médicas".

Tais terapias foram inicialmente demandadas por faixas populacionais jovens (20-35 anos) de classe média das grande cidades, em sua grande maioria com cultura universitária, relacionando-se com o estilo de "medicina naturista", que ganhou notoriedade nos anos $70 \mathrm{com}$ a chegada do movimento de contracultura à América Latina. Além de incluir as grandes medicinas tradicionais do Oriente, como a medicina tradicional chinesa e a ayurveda, geralmente reinterpretadas e reapropriadas culturalmente de acordo com padrões ocidentais, incluem também reinterpretações da homeopatia e da fitoterapia populares, vistas como formas mais "naturais" de tratar as doenças, sem o "perigo" da iatrogenia da medicina convencional para a saúde.

Atualmente esse terceiro grupo de "medicinas alternativas" é cada vez mais buscado por todas as camadas da população, tendo-se difundido das mais cultivadas para as menos educadas formalmente. Sistemas médicos como a homeopatia e a medicina tradicional chinesa, mais conhecidos entre nós que a ayurveda, tenderam a ser institucionalizados e inseridos nos serviços públicos de saúde no Brasil, apesar de resistências oriundas da corporação médica.

Os três grupos de medicinas alternativas descritos acima têm atuado em interação, competição ou complementação no meio cultural atual, que apresenta forte tendência ao sincretismo terapêutico, tanto do lado do paciente como do lado do terapeuta. Tendem também, ao menos no Brasil, a um certo sincretismo institucional nos serviços de saúde, ditando a medicina ocidental científica a "função terapêutica" das medicinas ditas alternativas. Sob esta ótica, sistemas médicos complexos tradicionais, que têm sua racionalidade específica, tendem a ser "decompostos" em alguns dos seus elementos diagnósticos ou (sobretudo) terapêuticos, e a serem utilizados pela clientela de acordo com um certo "bom senso" classificatório de suas demandas de cuidados e de tratamento de doenças.

Neste caso, não se leva em consideração a racionalidade própria desses sistemas, cujo paradigma é teoricamente centrado na terapêutica, empiricamente baseado na observação sistemática de pacientes singulares, e terapeuticamente orientado para a escuta de sujeitos doentes, no sentido de estabelecer seu diagnóstico, em geral considerado um processo individual de adoecimento ligado a padrões específicos classificáveis de desarmonia. 
A questão que se coloca, em termos socioantropológicos e mesmo filosóficos, em face dessas "medicinas alternativas", é a seguinte: em que poderiam essas medicinas, muitas vezes milenares, inovar, ou tornar-se, frente à nossa, em constante evolução tecnológica, um "novo modelo", ou trazer para a saúde das populações, neste fim de século e milênio, um "novo paradigma"? Poderiam efetivamente contribuir para superar, seja na diagnose, seja na terapêutica, uma medicina em revolução científica permanente? Em caso afirmativo, como e onde?

\section{Medicinas Alternativas e Novo Paradigma Médico}

Acredito que um novo paradigma médico pode nascer justamente ali onde a racionalidade médica ocidental esqueceu que era mais que um saber científico - isto é, que é também uma arte de curar sujeitos doentes, distanciando-se da sua dimensão terapêutica, na busca de investigar, classificar e explicar antigas e novas, sobretudo as novas, patologias através de métodos diagnósticos crescentemente sofisticados.

E na arte de curar predomina a terapêutica sobre a diagnose. Deste ponto de vista, as medicinas tradicionais, com sua racionalidade terapêutica específica, inovam, em termos de paradigma, quanto aos seguintes aspectos.

\subsection{Na reposição do sujeito doente como centro do paradigma médico}

A singularidade do paciente, visto como totalidade biopsíquica, bem como seu cuidado, tendem a ser considerados não apenas o objeto, mas também o objetivo central de medicinas como a homeopatia, a medicina tradicional chinesa e a ayurveda.

No momento atual da cultura contemporânea, a questão do cuidado tornou-se crucial para todos os indivíduos, seja o autocuidado, seja o heterocuidado, em que estão necessariamente incluídos os cuidados médicos. A generalidade e o distanciamento abstrato com que são tratados os pacientes da biomedicina, em função da centralidade da doença no paradigma da medicina científica, criaram uma barreira cultural para muitos indivíduos e grupos sociais, que demandam ser efetivamente tratados e não apenas diagnosticados. Não basta aos sujeitos doentes, ou em risco de adoecimento, saberem o nome da 
patologia que têm ou poderão vir a ter: precisam saber também se e como serão efetivamente cuidados para se curarem do mal ou não o contraírem. Em outras palavras, a questão da cura voltou a ser importante na cultura, e a medicina ocidental ainda não parece ter-se dado conta da importância desse evento para seu futuro desenvolvimento nas sociedades. As medicinas alternativas vêm ocupando o lugar deixado vago pela medicina convencional, e dispõem de muita experiência a transmitir nesse sentido.

\subsection{Na re-situação da relação médico-paciente como elemento fundamental da terapêutica}

Imediatamente decorrente do item anterior está a questão da relação médico-paciente, ou mais geralmente, da relação terapeuta-paciente. Essa relação também tende a ser pouco ou nada considerada na medicina ocidental contemporânea, que defende para essa relação a idéia de "objetividade" ou "neutralidade", tão cara à ciência. Num contexto de extrema sofisticação tecnológica quanto aos procedimentos diagnósticos e terapêuticos (exames, intervenções cirúrgicas ou paracirúrgicas etc.), interpõem-se máquinas de grande precisão entre o paciente e seu médico, estabelecendo-se uma "frieza" técnica na relação entre estes dois atores sociais. Entretanto, a relação terapeutapaciente é historicamente carregada de grande significação simbólica, inclusive quanto ao contato físico dos dois atores, o que implica o toque do corpo do paciente. No contexto de distanciamento atual, o paciente tende a ser visto e a sentir-se como um mero objeto de intervenção tecnocientífica, muitas vezes uma cobaia, despojado não apenas do seu corpo e de seu psiquismo, mas também de símbolos e significados pessoais e sociais investidos no seu adoecimento.

As medicinas alternativas, sobressaindo-se nesse caso a homeopatia, tendem a ver a relação médico-paciente como um elemento importante da cura, um guia seguro de indicação de evolução do tratamento. $\mathrm{O}$ aspecto psicológico, além do simbólico, é aqui evidentemente importante, e coloca para a medicina convencional uma questão crucial em face da eficácia médica e da resolutividade de questões de saúde da clientela de serviços públicos: grande parte dessa eficácia e resolutividade resulta da satisfação que os pacientes encontram no seu tratamento. Tal satisfação deriva, por sua vez, de uma relação socialmente complexa (em que estão presentes elementos simbólicos e subjetivos) estabelecida entre os dois termos. A satisfação não deriva, portanto, apenas de uma racionalidade tecnocientífica, que tende, aliás, a ignorar a 
dimensão humana envolvida na relação terapeuta-paciente. O sucesso das medicinas alternativas nos últimos quinze anos deriva, em grande parte, da maneira como essas medicinas estabelecem a relação com seus pacientes. Essa relação poderia servir como um parâmetro de discussão para a medicina institucional na atualidade, colocando-se em pauta a importância do aspecto simbólico em qualquer sistema terapêutico.

\subsection{Na busca de meios terapêuticos simples, despojados} tecnologicamente, menos caros e, entretanto, com igualou maior eficácia em termos curativos nas situações mais gerais e comuns de adoecimento da população

Sabe-se há pelo menos 20 anos que as questões mais importantes de saúde das populações do mundo inteiro, marcadamente em países do Terceiro Mundo, não são mais uma questão estritamente médica. Sabe-se, através de contribuições da medicina sanitária, que uma tecnologia relativamente simples, adquirida pela medicina há várias décadas, seria suficiente para enfrentar as doenças mais comuns nesses países - tanto as infecto-contagiosas quanto as crônicas.

Entretanto, as questões de saúde atuais mais amplas exigem, para enfrenta-las, não apenas políticas públicas infra-estruturais, ligadas ao saneamento e à educação, atualmente deixadas de lado pelos governos com a dominância mundial do neoliberalismo, como também modelos médicos pouco custosos, que possam assegurar práticas adequadas de promoção e recuperação da saúde. Tais modelos não fazem apelo à grande tecnologia atual, tão refinada quanto cara, ligada às especialidades médicas; muito pelo contrário, supõem uma visão mais globalizante e integrada da saúde dos cidadãos, atendendo-os com o que se designa comumente de modelo de atenção primária à saúde. Este atua de maneira mais simplificada tanto para a diagnose, dispensando a parafernália dos exames sofisticados, como para a terapêutica. Privilegia-se, como forma de intervenção prioritária a adoção, pela clientela, de práticas alternativas de saúde, hábitos e estilos de vida; hierarquizam-se ações, formas de intervenção, incentivando-se muitas vezes uma presença mais ativa do cidadão doente em face de sua doença, através de estratégias de socialização, como a formação de grupos de pacientes com troca de experiência e tomada de decisões para iniciativas de práticas coletivas, reuniões e discussões com terapeutas e especialistas etc. 
O novo modelo, inspirado em experiências sociais ligadas à associação de grupos comunitários e a ONGs, encontra em governos municipais que buscam a participação democrática em suas gestões, em sistemas geralmente locais de saúde, sua maior expressão. Enfrenta, no entanto, grande resistência da medicina hospitalocêntrica e dos interesses privados em atenção médica. Além disso, é muito prejudicado com o desmonte e a desestruturação dos serviços públicos de saúde em marcha nos anos 90, em função das novas políticas públicas.

No modelo referido às medicinas alternativas, tendem a ocupar um espaço crescente de institucionalização, na medida em que operam justamente com uma forma de diagnose e terapêutica tecnologicamente despojada, favorecedora do respeito ao paciente como cidadão e de sua autonomia. $\mathrm{Na}$ verdade, tal espaço vem sendo paulatinamente ocupado, sobretudo no Brasil, que adotou, em função das medicinas alternativas, uma legislação pioneira avançada, apesar do processo atual de degradação de sua rede pública.

O mais interessante a ser ressaltado, quanto ao aspecto organizacional, é a resolutividade que atividades com medicinas alternativas vêm obtendo em programas nos serviços públicos de atenção médica, diante da demanda da clientela, em relação a doenças crônicas (ou mesmo em relação a distúrbios funcionais), tradicionalmente com baixa resolutividade nos serviços convencionais, como em casos de doenças circulatórias, reumatismos, ou problemas osteo-articulares, diabetes, renais crônicos etc. Certamente o modelo diagnóstico-terapêutico dessas medicinas é um elemento explicativo fundamental dessa resolutividade.

\subsection{Na construção de uma medicina que busque acentuar a} autonomia do paciente, e não sua dependência em termos da relação saúde/enfermidade

As medicinas alternativas, aí salientando-se sobretudo as de sistema complexo, que conformam, como afirmei, uma racionalidade médica, como a homeopatia, a medicina tradicional chinesa e a medicina ayurvédica, trabalham com um paradigma centralizado na saúde, e não na doença, como a biomedicina. A centralidade da saúde tem conseqüência importante em relação ao objetivo e ao objeto central dessas medicinas.

O objetivo principal da intervenção médica passa a ser a recuperação e/ou a promoção da saúde dos sujeitos, e o objeto central do agir médico passa 
a ser o sujeito doente, visto como um todo biopsíquico, se quisermos empregar uma expressão cara à medicina psicossomática ou, numa expressão mais próxima à Antropologia, uma unidade socioespiritual, inserida numa cultura específica, na qual esse sujeito deve viver e atuar. Não se trata de simplesmente combater ou erradicar doenças: trata-se de incentivar a existência de cidadãos saudáveis, capazes de interagir em harmonia com outros cidadãos, e de criar para si e para os que lhe são mais próximos um ambiente harmônico, gerador de saúde.

Em princípio tais medicinas tendem a propiciar um conhecimento maior do indivíduo em relação a si mesmo, de seu corpo e de seu psiquismo, com uma consequiente busca de maior autonomia em face de seu processo de adoecimento, facilitando um projeto de construção (ou de reconstrução) da própria saúde.

Esse processo se torna claro quando se entrevistam pacientes de homeopatia da rede pública ${ }^{6}$. Também se pode notar o mesmo processo em pacientes da medicina ayurvédica em hospital público ${ }^{7}$. Já na medicina tradicional chinesa, por outro lado, é com a prática dos exercícios derivados das artes marciais, como o tai chi chuan, que se nota esse tipo de mudança, pela qual o paciente passa a ser menos dependente de remédios e de médicos, tornando-se um agente de cura de si mesmo. Os outros tipos de terapêutica da medicina chinesa, como a massagem e a acupuntura, por sua própria natureza, facilitam a passividade. Diante da nossa medicina ocidental, que tende a estabelecer uma relação de heteronomia dos sujeitos em relação à sua saúde, e até mesmo em relação ao seu próprio corpo, acredito que as medicinas alternativas dispõem, na atualidade, de um manancial de. informações e de postura terapêutica frente aos cidadãos doentes que não deve ser ignorado, muito menos desprezado.

\subsection{Na afirmação de uma medicina que tenha como categoria central de seu paradigma a categoria de Saúde e não a de Doença}

Finalmente, cabe assinalar a questão conceitual básica, que define as medicinas alternativas aqui examinadas, como racionalidade distinta da hegemônica em nossa cultura. É a questão da centralidade das categorias de Vida, Saúde e Equilíbrio (ou Harmonia) no seu paradigma de conhecimento e de prática terapêutica.

A centralidade dessas categorias está presente não apenas na dimensão terapêutica dessas medicinas, como também nas dimensões da diagnose, da 
doutrina médica, da dinâmica vital e da própria morfologia humana. Em outras palavras, trata-se de racionalidades médicas que claramente adotam um paradigma vitalista na abordagem dos processos de adoecimento e cura dos sujeitos, estabelecendo para a medicina (ou reestabelecendo, conforme sua tradição milenar) o papel de promotora e recuperadora da saúde, de auxiliar da vida, e não simplesmente de investigadora e combatente de entidades nosológicas, de patologias.

Apesar de se distanciarem quanto a esse aspecto, e mesmo se oporem ao caráter essencialmente patologizante da biomedicina em sua atualidade, essas medicinas alternativas podem, com sua racionalidade específica, regida por um paradigma vitalista, auxiliar na reconstrução conceitual da medicina, ajudandoa, neste fim de milênio, a retomar sua função terapêutica primordial frente à saúde das populações e, indiretamente, em face do grande processo da continuidade da vida humana em nosso planeta.

\section{A Legitimação e a Institucionalização das Medicinas ou Terapias Ditas Alternativas a Partir dos Anos 80}

Os anos 80 assinalaram um marco fundamental nas relações entre saber médico oficial, sociedade política e sociedade civil em alguns países do continente. É o caso do Brasil que me interessa analisar aqui, porque penso e reafirmo que este país vem tendo um papel pioneiro no reconhecimento das chamadas medicinas alternativas no continente.

$\mathrm{Na}$ sociedade brasileira, com efeito, em função do processo de redemocratização política em curso na década de 80, o Estado tornou-se sensível aos movimentos sociais e às demandas da sociedade civil perante as políticas públicas. No tocante à saúde, esses movimentos foram de uma intensidade inédita, considerada a abrangência dos setores sociais envolvidos, e a qualidade e radicalidade das reivindicações colocadas para o setor público.

No que concerne à sociedade civil não organizada, o que costumamos denominar de "clientela" em saúde, constatou-se uma formação de demanda, com a nítida estruturação de um mercado do que se designa comumente de bens de cura, favorecendo as medicinas alternativas, entre as quais devem ser destacadas a homeopatia, secularmente existente na sociedade brasileira, a acupuntura e a fitoterapia. Há também outras práticas terapêuticas oriundas do grande boom contraculturalista dos anos 70 nos Estados Unidos, como a terapia 
dos cristais, das cores, dos florais, da "regressão a vidas passadas" etc., consumidas sobretudo pelos setores cultivados da classe média, mas com grande tendência à generalização por difusão, considerando-se o papel de formadores de opinião desses setores.

Tanto os movimentos organizados da sociedade civil, seja em associações comunitárias, seja posteriormente em ONGs, como a demanda social da clientela para serviços públicos de saúde crescentemente pressionaram as instituições médicas no sentido de uma "abertura" para as medicinas ditas alternativas nos anos 80. De tal modo que em meados da década passada, em agosto de 1985, a homeopatia, a fitoterapia e a medicina tradicional chinesa, através da acupuntura, foram legitimadas nos serviços médicos da previdência social, através de um convênio celebrado pelo então presidente do Instituto Nacional de Assistência Médica da Previdência Social (INAMPS) e o ministro da Previdência Social, com instituições acadêmicas como a Fiocruz e a UERJ, além do Instituto Hahnemanniano Brasileiro (IHB), no sentido de se estabelecerem-se atividades não apenas de atendimento médico envolvendo homeopatia, acupuntura e fitoterapia, mas também atividades de pesquisa e ensino sobre essas "medicinas alternativas".

A história desse processo de institucionalização vem-se inscrevendo com muitos percalços na última década no Brasil, tendo seu percurso encontrado obstáculos constantes interpostos pela medicina socialmente hegemônica. Nessa obstaculização, o saber médico científico funciona como elemento às vezes de censura, às vezes de comprovação. Em geral, as instituições ligadas à reprodução do saber biomédico, como as faculdades de Medicina, ou os hospitais, são as que mais se opõem à inserção de medicinas alternativas em espaços institucionais. Entretanto, não raras vezes as instituições mais avançadas de pesquisa biomédica empreendem investigações visando à eventual comprovação de procedimentos ou princípios terapêuticos ligados às medicinas nãoconvencionais.

\section{Encontros e Tensões da Medicina Hegemônica com as Medicinas Alternativas}

Algumas hipóteses socioantropológicas podem ser esboçadas no sentido de explicar o sucesso social e institucional das medicinas alternativas, bem como os obstáculos que encontram no caminho de seu reconhecimento, para 
além da crise apontada no início deste texto. Esquematicamente, poderia apresentar as seguintes:

a) Está havendo um encontro cultural das medicinas tradicionais com as novas representações e concepções aqui descritas, de saúde, adoecimento e cura, e relações homem/natureza, presentes atualmente na sociedade civil, tanto nas camadas sociais superior, média e inferior, como em diversos grupos sociais específicos, geralmente, mas não necessariamente portadores de educação formal superior.

Tal encontro tende a ser progressivamente absorvido pelas instituições médicas, de acordo com a conjuntura política, através dos governos centrais ou locais de países do continente latino-americano. Essa absorção depende, por sua vez, de demanda social e de pressão política em favor de medicinas alternativas e sua legitimação. Tal pressão pode ser exercida através de meios de difusão de massa, ou através de movimentos sociais que buscam alternativas em saúde. Essa pressão tende a encontrar, no entanto, a contrapressão oriunda da corporação médica, que geralmente se opõe à legitimação de medicinas alternativas, a não ser que tal legitimação se faça através do seu reconhecimento como "especialidade médica" - isto é, como um saber e uma prática médica a serem exercidos e controlados pelos médicos. Foi o que aconteceu no Brasil com a homeopatia, em 1980, e é o que está acontecendo agora, na segunda metade dos anos 90, com a acupuntura, dimensão terapêutica da medicina tradicional chinesa.

b) As medicinas alternativas vêm funcionando como um modelo atraente de relação terapeuta/paciente para um setor dos médicos ocidentais, aqueles comprometidos com a questão da arte de curar. Além disso, atraem numerosos candidatos a terapeutas num florescente "mercado de cura".

A crise prática da medicina no seu plano ético, isto é, da prática terapêutica, em função da qual o paciente é deixado em segundo plano em face da pesquisa de novas patologias, ou mesmo de novos vírus ou bactérias, deixou órfã toda uma geração de médicos terapeutas, muitas vezes partidários da contracultura dos anos 70 . Esses médicos com vocação terapêutica encontraram nas medicinas alternativas, basicamente na homeopatia e na acupuntura, no que concerne ao Brasil, uma saída para o exercício dessa vocação. É verdade que encontraram também, nos anos 80 , um veio de mercado pouco explorado e com grande demanda potencial em termos de clientela privada. $\mathrm{O}$ fato é que essa situação contribuiu para que a formação em medicinas alternativas 
funcionasse como um pólo atrativo para estudantes de medicina desde o fim dos anos 70 .

Além disso, a cultura do "cuidado de si" que marcou as últimas décadas, fazendo com que os indivíduos, sobretudo os de classe média, buscassem cuidados terapêuticos como um bem de consumo prioritário, foi um dos elementos sociais de base para a criação de um grande mercado de cura "alternativa", com expressiva oferta de novos terapeutas não-médicos.

Entre esses novos terapeutas destacam-se os psicólogos, abundantes no mercado de trabalho da cura, em função da crise dos saberes "psi" dos últimos vinte anos. Entretanto, não são apenas os psicólogos que buscam formação em diferentes terapias "alternativas", como a bioenergética, os florais de Bach, a cristaloterapia, a cromoterapia etc. Diversos profissionais com formação superior, como assistentes sociais, professores, às vezes biólogos, ou mesmo farmacêuticos, candidatam-se aos cursos de formação em "medicinas alternativas". Também um grande número de candidatos a terapeutas em massagens, acupuntura, exercícios e artes marciais, sem formação no ensino superior, demandam a formação em medicinas ou terapias alternativas como uma porta de entrada no mercado de trabalho terapêutico atual. É esta porta que os médicos querem fechar, mantendo as chaves nas mãos da corporação médica. Uma série de encontros, confrontos e polêmicas vêm resultando desse amplo processo de reorientação das relações entre sociedade e medicina, ou pelo menos entre cultura, saúde e cura.

c) Há um crescimento progressivo, nos últimos quarenta anos, de concepções e teorias psicossociais do adoecimento no interior da própria medicina contemporânea. Esse crescimento pode manifestar uma busca de superação da clássica dicotomia corpo/mente da cultura ocidental.

O surgimento e o grande desenvolvimento da chamada medicina psicossomática a partir da segunda metade do século XX é, do meu ponto de vista, uma clara manifestação dessa busca. Através dessa disciplina é impossível explicar o adoecer humano apenas biologicamente, assim como é impossível recuperar sua saúde sem levar em consideração os aspectos psíquicos que levam o ser humano a se tomar doente dessa ou daquela doença.

Independentemente dessa disciplina, os saberes "psi" (psicologia, psiquiatria e, sobretudo, a psicanálise) têm exercido influência, se não no saber médico, ao menos na prática dos clínicos, chamando a atenção para a 
importância das emoções e dos sentimentos nos fenômenos de adoecimento e de cura. Gera-se, com isso, uma série de pesquisas sobre o efeito de certos sentimentos (a angústia, o medo, a raiva etc.) e do stress, no desencadear de um conjunto de sintomas e crises de doenças cardiovasculares, respiratórias, renais etc.

Acredito que o desenvolvimento dessas concepções e teorias no interior do próprio saber médico tem favorecido abordagens holísticas do adoecer e do tratar, típicas das medicinas ditas alternativas, pois "abre" o campo explicativo da medicina para outros paradigmas, distintos do paradigma "duro" da biomedicina.

d) Há uma incorporação crescente pelo saber médico das concepções e explicações médico-sociais na etiologia das doenças no século XX, através da epidemiologia e do modelo médico sanitarista. Tal incorporação favorece as abordagens terapêuticas menos medicalizadoras.

A epidemiologia tornou-se um dos pilares fundamentais do saber médico no século XX, sobretudo a partir da sua segunda metade, com o refinamento dos instrumentos de pesquisa biomédica e o apoio decisivo da clínica ao modelo epidemiológico, de busca do conhecimento e do controle das doenças coletivas como finalidade básica da medicina.

Entretanto, a epidemiologia tem uma parte de suas raízes conceituais mergulhada em ciências sociais clássicas, como a Demografia, a História, a Geografia, e mesmo em disciplinas do campo do século XIX, como a Sociologia e a Antropologia. A causalidade social das doenças faz parte de seu paradigma, de seu olhar coletivizante sobre o adoecimento humano, se se pode dizer assim. Por outro lado, a explicação de tal adoecimento por fatores socioculturais, como comportamentos, hábitos e atitudes, ou por estruturas sociais e seus efeitos, como pobreza, ignorância, infra-estrutura sanitária deficiente etc., explicação típica do modelo médico sanitarista, impede que se possa reduzir a explicação diagnóstica, ou a abordagem terapêutica das doenças de populações, a puros fatores médicos.

Do meu ponto de vista, essa abordagem, crescentemente incorporada ao saber médico, favorece a superação do paradigma clássico da biomedicina, embora não favoreça as medicinas alternativas, devido a seu grande cientificismo.

e) A tudo isto deve se acrescentar a mencionada dupla crise, da saúde e da medicina, exposta na parte introdutória deste artigo, com a qual o modelo 
biomédico tem de contar para enfrentar os problemas cotidianos de saúde dos países do continente. Isto tem levado as instituições médicas a buscar, ou pelo menos a aceitar e sancionar, formas alternativas de atenção médica às populações desses países.

A adoção de modelos de atenção primária em serviços públicos de saúde, na América Latina, desde os anos 70, destinados às populações de baixa renda, não gerou apenas polêmica. Tem gerado também formas alternativas de atendimento, de diagnose e de intervenção terapêutica, distintos do modelo altamente sofisticado, do ponto de vista tecnológico, da medicina hospitalocêntrica especialista. Essas novas formas tendem a instituir, do meu ponto de vista, novos modelos de relação terapeuta-paciente e serviços de saúde/clientela. Tendem também a valorizar procedimentos despojados em diagnose e terapêutica.

O modelo do médico de família inspirado na experiência cubana, que começa a ser introduzido no Brasil, o modelo de atenção multiprofissional (médicos, nutricionistas, psicólogos, assistentes sociais etc.) a grupos de pacientes portadores de doenças crônicas, o modelo de discussão grupal de pacientes doentes da mesma doença, orientados por um assistente social ou um psicólogo, são alguns exemplos, entre os vários modelos de atendimento em serviços públicos que estão sendo postos em experiência em programas municipais, desde os anos 80, no Brasil.

Em todos esses exemplos, os procedimentos terapêuticos privilegiam a medicina preventiva, em termos de hábitos e comportamentos higiênicos, alimentares etc., e tendem a privilegiar outros procedimentos em terapêutica, para além do medicamento, que permitam superar o modelo puramente medicalizador. Penso que os programas com os novos modelos de atendimento favorecem potencialmente as medicinas alternativas já institucionalizadas, como a homeopatia, a fitoterapia e a medicina tradicional chinesa, sobretudo em sua modalidade terapêutica de exercícios.

Finalmente, deve ser ressaltado que em algumas especialidades médicas, como a pediatria, a dermatologia, a alergologia e a própria cardiologia, médicos especialistas têm aceitado a contribuição das "medicinas alternativas", como a homeopatia, a medicina tradicional chinesa e a fitoterapia tradicional como procedimentos terapêuticos complementares, e mesmo alternativos aos de sua especialidade, considerados por esses profissionais excessivamente iatrogênicos ou ineficientes do ponto de vista custo/benefício. Isto não significa, entretanto, 
que nos serviços onde há programas de medicinas alternativas esteja havendo um referenciamento automático dessas especialidades para as terapêuticas alternativas. Até o presente momento as atividades desses programas continuam institucionalmente isoladas, quando não são bloqueadas pelos profissionais médicos. A referência para os programas vem por intermédio de funcionários ligados aos serviços, familiares de pacientes, e, evidentemente, pela mídia.

$\mathrm{Na}$ verdade, os bloqueios continuam muito mais presentes que os encontros, no que concerne às medicinas tradicionais, ditas alternativas, diante da medicina dita científica. Esses bloqueios se fazem sentir com mais intensidade nos situs institucionais acadêmicos, de produção e reprodução do saber médico hegemônico, como nos institutos de pesquisa e nas faculdades da área biomédica (Medicina, Enfermagem, Farmácia, Nutrição, Odontologia), com evidente liderança da Medicina.

Muitas tentativas vêm sendo feitas no Brasil, desde os anos 70, para mencionar apenas este século, para se instalarem, nas faculdades de Medicina, disciplinas em Homeopatia, Acupuntura ou Fitoterapia. Os avanços têm sido muito lentos e ainda pouco consideráveis do ponto quantitativo, mas existem.

Em relação à questão do ensino, um dos cenários possíveis é haver a incorporação, ao longo das próximas décadas, dessas medicinas como opcionais, com a provável superação, ou pelo menos diminuição, da atual dicotomia diagnose/terapêutica que caracteriza a racionalidade médica ocidental. Neste caso, em relação ao saber médico, a terapêutica retomaria seu lugar, perdido nos últimos séculos para a diagnose, e a arte de curar retomaria sua função de finalidade básica da medicina, em face da ciência das doenças hoje dominante. Este é um cenário que sei ser otimista, porém possível, como saída para a dupla crise apontada no início deste trabalho. Nesse cenário otimista, as medicinas alternativas tenderiam a conviver com a medicina hegemônica não apenas na sociedade civil, no "mercado de cura", mas também na sociedade política, nos serviços públicos, através de sua incorporação como recursos terapêuticos válidos e elegíveis como direito de cidadania, como já estabelece a atual Constituição brasileira.

Com essa convivência, que se estabeleceria nas próximas décadas, a medicina ocidental poderia recuperar vários elementos de seu paradigma clássico, a partir do aprendizado com as medicinas tradicionais, aí incluída a própria homeopatia. O risco nesse caso, é o de "sincretismo médico", com possível perda de sua racionalidade para as medicinas alternativas, em proveito da 
biomedicina $^{8}$. O principal desses elementos recuperáveis pela medicina, de natureza simbólica e prática, é a re-situação do paciente como centro de seu objeto de investigação e objetivo de intervenção terapêutica.

A recuperação da relação médico/paciente, hoje danificada pela medicina transformada em biotecnologia, seria uma consequiência imediata desta re-situação. Neste caso, a escuta do paciente, ou dos pacientes, se tomados em grupo, constituir-se-ia, de novo, nas fontes privilegiadas e primárias da investigação e acumulação de dados da clínica, valorizando-se novamente o agir do médico, a ser visto mais como um terapeuta que como o investigador de patologias do presente.

\section{Referências}

ALMEIDA, E. L.V. Medicina hospitalar / medicina extra-hospitalar: duas medicinas? Dissertação (Mestrado em Saúde Coletiva) - Instituto de Medicina Social da Universidade do Estado do Rio de Janeiro, Rio de Janeiro, 1988.

ALMEIDA FILHO, N. Epidemiologia sem números. Rio de Janeiro: Campus, 1989.

ALMEIDA FILHO, N. As razões da terapêutica. Tese (Doutorado em Saúde Coletiva) - Instituto de Medicina Social da Universidade do Estado do Rio de Janeiro, Rio de Janeiro, 1996.

BACHELARD, G. L. La formación dei Espíritu Científico. Mexico: Siglo Veintiuno, 1985.

BALINT, M. O médico, seu paciente e a doença. Rio de Janeiro: Ateneu, 1975.

CAMARGO JR., K. R As ciências da AIDS e a AIDS das ciências. Rio de Janeiro: Relume-Dumará, 1994.

CAMARGO JR., K. R A medicina ocidental contemporânea. Cadernos de Sociologia, Porto Alegre, v. 7, p. 129-150, dez. 1995.

CANGUILHEM, G. O normal e o patológico. Rio de Janeiro: Forense Universitária, 1981.

CHAUVEnNett, A. A lei e o corpo. Physis: Revista de Saúde Coletiva. Rio de Janeiro, v. 1, n. 1, p. 131-148, 1991. 
CLAVREUL, J. A. A ordem médica. Rio de Janeiro: Brasiliense, 1983.

COULTER, H. Divided legacy: the schism in medical thought. Berkeley, CA: North Atlantic Books, 1982.

DASH, V. B. Fundamentais of Ayurvedic medicine. New Delhi: Konark Publ. PVT, s/d.

DASH, V. B.; JUNIUS, A. M. M. A handbook of Ayurveda. New Delhi: Concept Publ. Co., 1987.

EDDE, G. La medicine Ayurvedique. St. Jean-de-Braye: Dangles, 1985.

FOUCAULT, M O nascimento da clínica. Rio de Janeiro: Forense Universitária, 1978.

FOUCAULT, M. Microfísica do poder. Rio de Janeiro: Graal, 1981.

FRAWLEY, D. Ayurvedic healing: a comprehensive guide. Salt Lake City: Passage Press, 1989.

GINZBURG, C. Mitos, emblemas, sinais. São Paulo: Companhia das Letras, 1989.

GONÇALVES, P. E. (Org.). Medicinas alternativas: tratamentos nãoconvencionais. São Paulo: Ibrasa, 1989.

HABERMAS, J. Conhecimento e interesse. Rio de Janeiro: Guanabara, 1987.

HAlINEMANN, S. Organon de la medicina. New Delhi: B. Jain Publishers, 1993.

HERZLICH, C. A problemática da representação social e sua utilidade no campo da doença. Physis: Revista de Saúde Coletiva. Rio de Janeiro, v. 1, n. 2, p. 23-34, 1991.

KENT, J. Lesser Writings. New Delhi: B. Jain Publishers, 1976.

KENT, J. Filosofia de la Homeopatia. Buenos Aires: El Ateneo, 1982.

LUZ, D. A medicina tradicional chinesa (MTC). Rio de Janeiro: IMS/UERJ, 1993 (Série Estudos em Saúde Coletiva, 72).

LUZ. H. S. Homeopatia e racionalidade médica. Revista da Associação Paulista de Homeopatia. São Paulo, v. 60, n. 3-4, p. 3-13, 1995. 
LUZ. M. T. Natural, racional, social: razão médica e racionalidade científica moderna. Rio de Janeiro: Campus, 1988.

LUZ. M. T. A arte de curar e a ciência das doenças: história social da homeopatia no Brasil. Rio de Janeiro: Abrasco, 1996.

LUZ, M. T. et al. I Seminário do Projeto Racionalidades Médicas. Rio de Janeiro: IMS/UERJ, 1992. Mimeo.

LUZ, M. T. et al. II Seminário do Projeto Racionalidades Médicas. Rio de Janeiro: IMS/UERJ, 1992. Mimeo.

LUZ, M. T. et al. III Seminário do Projeto Racionalidades Médicas. Rio de Janeiro: IMS/UERJ, 1993. Mimeo.

LUZ, M. T. et al. IV Seminário do Projeto Racionalidades Médicas. Rio de Janeiro: IMS/UERJ, 1994. Mimeo.

LUZ, M. T. Racionalidades médicas e terapêuticas alternativas. Cadernos de Sociologia, Porto Alegre. v. 7, p. 108-128, dez. 1995.

LUZ, M. T. et al. V Seminário do Projeto Racionalidades Médicas. Rio de Janeiro: IMS/UERJ, 1996 (Série Estudos em Saúde Coletiva, 136).

LUZ, M. T. et al. VI Seminário do Projeto Racionalidades Médicas. Rio de Janeiro: IMS/UERJ, 1996 (Série Estudos em Saúde Coletiva, 140).

MACHADO, R. Ciência e saber. Rio de Janeiro: Zahar, 1982.

MARKERT, C. Yin e Yang: Polaridade e harmonia em nossa vida. São Paulo: Cultrix, 1983.

NEEDHAM, J. De la ciencia y Ia tecnología chinas. Mexico: Siglo Veintiuno, 1978.

PAGE, M. CH'I - Energia vital. São Paulo: Pensamento, 1991.

POITEVIN, B. Le devenir de l'homéopathie (éléments de théorie et de recherche). Paris: Doin, 1987.

QUEIROZ, M. Representações sobre saúde e doenças. Agentes de cura e pacientes no contexto do SUDS. Campinas: Unicamp, 1991.

RODRIGUES, R. D. A crise da medicina: prática e saber. Rio de Janeiro: IMS, 1979. 
ROSSI, P. A ciência e a filosofia dos modernos. São Paulo: Unesp, 1992. STENGERS, I. Que tem medo da ciência? São Paulo: Siciliano, 1991.

TAMAYO, R. P. El concepto de enfermedad. Mexico: Fondo de Cultura Econômica, 1988.

UNSCHULD, P. Medicine in China: a history of ideas. Los Angeles: University of California Press, 1985.

VITHOUKAS, G. La science de l'homéopathie. Monaco: Rocher, 1980.

WEBER, M. A ética protestante e o espírito do capitalismo. São Paulo: Pioneira, 1967.

ZIMMER, H. Mitos e símbolos na arte e civilização da Índia. Compilado por Joseph Campbell. São Paulo: Palas Athena, 1989.

\section{NOTAS}

${ }^{1}$ Este artigo foi apresentado em forma de Comunicação ao IV Congresso Latino-Americano de Ciências Sociais e Medicina, realizado em Cocoyoc, México, em junho de 1997. Algumas modificações e revisões foram feitas ao texto original. Este trabalho é devedor das sugestões, afirmações e observações, conceituais e factuais, sobretudo no que se refere a medicinas tradicionais indígenas, escritas para o presente trabalho pelo professor Raul Mideros Morales, da Universidade Andina Simon Bolivar, Quito, Equuador. Várias de suas sugestões foram incorporadas ao texto, tomando-o parcialmente fruto de sua colaboração. Publicado em Physis, v. 7, n. 1, p. 13-43, 1997.

${ }^{2}$ Socióloga, professora titular do Departamento de Políticas e Instituições de Saúde do Instituto de Medicina Social da UERJ. E-mail: madelluz@ superig.com.br

${ }^{3}$ Michel Joubert, do Departamento de Sociologia da Universidade de Paris 8, desenvolveu, com outros sociólogos de sua equipe, na associação de pesquisas RESSCOM (Recherches et Evaluations Sociologiques sur lê Social, la Santé et les Actions Communautaires) um projeto de pesquisa aprovado pelo Instituto Nacional de Estatísticas e Estudos de Populações da França (INSEE), durante a primeira metade dos anos 90, um que uma enquête sociodemográfica constatou a presença de uma mal-estar difuso presente em grande parte da população urbana trabalhadora, desempregada ou aposentada. 
${ }^{4}$ A categoria Racionalidade Médica foi por mim e minha equipe de pesquisa do Instituto de Medicina Social da UERJ construída entre 1991 e 1992 para o projeto "Racionalidades Médicas", um estudo comparativo de quatro sistemas médicos complexos: a Medicina Ocidental Contemporânea, ou Biomedicina, a Medicina Homeopática, a Medicina Tradicional Chinesa e a Medicina Ayurvédica. Essa categoria, construída ao estilo. de um tipo ideal weberiano, estabelece que toda racionalidade médica supõe um sistema complexo, simbólica e empiricamente estruturado de cinco dimensões: uma morfologia humana (na medicina ocidental definido como anatomia); uma dinâmica vital (entre nós definida como fisiologia); uma doutrina médica; um sistema de diagnose; e um sistema de intervenção terapêutica. Com o desenrolar da pesquisa, descobriu-se uma -sexta dimensão, que embasa as anteriores, e que pode ser designada como cosmologia.

${ }^{5}$ É verdade que há várias outras práticas de cura derivadas de religiões nas sociedades sulamericanas, sobretudo no Brasil, onde os cultos protestantes se estabeleceram solidamente a partir da década de 80 , com suas curas exorcistas. Há também práticas neo-xamanistas, ligadas às "seitas do vegetal", oriundas da Amazônia, desenvolvidas em grandes centros urbanos como Rio de Janeiro e São Paulo, a partir da última década. Não constituem, entretanto, sistemas médicos complexos, que designo neste trabalho como "medicinas alternativas", sendo simplesmente práticas terapêuticas.

${ }^{6}$ A pesquisa "Racionalidades Médicas” realizou entrevistas com pacientes de serviços públicos de homeopatia em nove unidades no município do Rio de Janeiro, entre 1994 e 1996 (entrevistas de primeira e segunda vez). Ficou evidente a constituição, durante o tratamento, do que se poderia chamar de um "projeto" de saúde para a maioria dos pacientes. O mesmo não se verifica com os pacientes da Medicina Ocidental, ou biomedicina, ou com os pacientes da acupuntura, que vão aos serviços apenas para resolver problemas de dor, ou osteomusculares, conforme atribuição terapêutica delegada à MTC. nas unidades públicas de atendimento. Quando os pacientes praticam os exercícios, como o Tai Chi Chuan, ao contrário, a perspectiva de "projeto de saúde" aparece, sobretudo, entre idosos.

${ }^{7}$ A única experiência com a qual tivemos contato, neste sentido, foi com a do Hospital de Medicina Alternativa de Goiânia, integrado ao SUS brasileiro, que tem dez anos de trabalho com pacientes da rede pública, na qual o mesmo resultado, isto é, o da autonomia do paciente em relação a seu processo saúde/doença, com a constituição de um "projeto de saúde", tende a aparecer.

${ }^{8}$ Deve ser ressaltado, entretanto, que tal processo é quase inevitável na cultura contemporânea, dita pós-moderna, em que fragmentação e sincretismo são formas dinâmicas características de integração cultural. 
Contemporary Culture and Complementary Medicine: New Paradigm in Health in the End of the Century

This article deals with the relationships between culture and medicine, and the great spread of alternative medicine in present days. It intends to explain this spread in a sociological approach, trying to advance two basic hypotheses: the first one concerns the present double crisis in health and medicine, and the second one concerns the search for a new rationale in health and care by both patients and therapysts in our contemporary society. It seems to exist a clear cultural lag between cultural changes in practices and representations in health, healing and care and the direction of medical progress.

Key words: Culture; medicine; alternative medicine. 